\title{
Desenvolvimento de competências: a percepção de gestores sobre técnicos administrativos em uma universidade federal
}

No serviço público, a atual configuração das relações humanas e das ferramentas intangíveis de trabalho, que estão dispostas aos servidores, deveriam ser responsáveis pelo bom desempenho do serviço prestado. Políticas de Gestão de Pessoas, sobretudo de Planos de Carreira, deveriam se configuram como fatores-chave de sucesso nas organizações. Neste sentido, nas Instituições Federais de Ensino Superior, o Plano de Cargos e Carreiras dos Técnicos Administrativos em Educação - PCCTAE, enquanto plano de carreira, pretendeu estimular o desenvolvimento profissional dos servidores aliado aos objetivos estratégicos destas instituições. Dado este contexto, o presente estudo se preocupa em avaliar o comportamento no desenvolvimento da carreira dos Técnicos Administrativos em Educação a partir da percepção da alta gestão de uma universidade federal, sob uma perspectiva de desenvolvimento de competências em consonância com os objetivos estratégicos institucionais. Utilizando-se de entrevistas semiestruturadas com a alta gestão de uma universidade federal como forma de coleta de dados, e valendo-se da análise de conteúdo como metodologia de análise dos dados, os resultados evidenciaram a percepção dos entrevistados que o conceito de competências no serviço público está fortemente relacionado a fatores socioemocionais apontando atitudes e valores que orientam o comprometimento e capacidade de trabalho em grupo como essenciais ao desempenho de qualquer profissão no serviço público. Quanto às possibilidades de aperfeiçoamento profissional por meio de cursos de capacitação e qualificação, foram encontradas críticas dos entrevistados a respeito da incompatibilidade dos cursos realizados em relação às atividades profissionais desenvolvidas no exercício do cargo. Já para os casos de concessões de licenças aos técnicos, as dificuldades relativas ao número restrito de servidores nas unidades administrativas, bem como da ausência de elementos que garantam a contratação temporária de força de trabalho substituta, destacam-se como fatores que atuam em detrimento ao desenvolvimento profissional dos TAEs. Segundo os entrevistados, ao longo dos 14 anos de implantação do PCCTAE, fora relatado que os elementos de progressão na carreira têm impacto fortemente financeiro e pouco voltados aos interesses institucionais, haja vista a ausência de uma política institucional de desenvolvimento de pessoal que, se implantada, permita aos servidores e à administração superior, alinharem e pactuarem a necessidade de desenvolvimento, levando-se em conta não somente as necessidades individuais dos técnicos, mas também, o desenvolvimento de competências que estejam alinhadas com o alcance dos objetivos estratégicos da instituição.

\section{Skills Development: Managers' Perception of Administrative Technicians at a Federal University}

\begin{abstract}
In the public service, the current configuration of human relations and intangible working tools, which are available to servers, should be responsible for the good performance of the service provided. People Management policies, especially Career Plans, should be key success factors in organizations. In this sense, in the Federal Institutions of Higher Education, the PCCTAE Careers and Careers Plan, as a career plan, intended to stimulate the professional development of the employees allied to the strategic objectives of these institutions. Given this context, the present study is concerned with assessing the career development behavior of Administrative Technicians in Education from the perception of senior management of a federal university, from a perspective of competence development in line with the institutional strategic objectives. Using semi-structured interviews with the senior management of a federal university as a form of data collection, and using content analysis as a data analysis methodology, the results showed the interviewees' perception that the concept of competencies in the service Audience is strongly related to socio-emotional factors pointing to attitudes and values ? that guide commitment and ability to work in groups as essential to the performance of any profession in the and qualification courses, criticism was fou of the courses taken in relation to the professional activities developed in the exercise of the position. In the case of licensing of technicians, the difficulties related to the restricted number of employees in the administrative units, as well as the lack of elements that guarantee the temporary hiring of a substitute workforce, stand out as factors that act against the professional development of TAEs. According to the interviewees, over the 14 years of the PCCTAE's implementation, it was reported that career advancement elements have a strong financial impact and little focus on institutional interests, given the absence of an institutional personnel development policy that, if implemented, allow employees and senior management to align and agree on the need for development, taking into account not only the individual needs of technicians, but also the development of competencies that are aligned with the achievement of the institution's strategic objectives.
\end{abstract}

Keywords: Career Plans; Skills; People management; Administrative Technicians in Education

Topic: Gestão Pública

Reviewed anonymously in the process of blind peer

Renato César de Souza Júnior (iD

Universidade Federal de Uberlândia, Brasil http://lattes.cnpq.br/3783887588960219

http://orcid.org/0000-0001-8922-5895

renatocesar@ufu.br

José Eduardo Ferreira Lopes

Universidade Federal de Uberlândia, Brasil

http://lattes.cnpq.br/1181111177305483

http://orcid.org/0000-0001-5504-3321

jeflopes@ufu.br

d

DOI: 10.6008/CBPC2179-684X.2019.003.0005
Received: 09/07/2019

Approved: 09/09/2019
Referencing this:

SOUZA JÚNIOR, R. C.; LOPES, J. E. F.. Desenvolvimento de competências: a percepção de gestores sobre técnicos administrativos em uma universidade federal. Revista Brasileira de Administração Científica, v.10, n.3, p.53-70, 2019. DOI:

http://doi.org/10.6008/CBPC2179-684X.2019.003.0005 


\section{INTRODUÇÃO}

O século XXI, denominado 'Era do Conhecimento', é marcado pela aceleração da globalização e alterações nas relações sociais e econômicas, cuja valorização se desloca para ativos intangíveis. Estas transformações colocaram em destaque a relevância de tais ativos e do comportamento humano para melhor desempenho das organizações (BARRETO, 2011; COSTA et al., 2011). Dentro deste contexto, as mudanças nas relações organizacionais aumentaram a relevância do capital intelectual, e o surgimento de novas tecnologias acabaram por trazer a necessidade acelerada e constante de aprendizagem individual e organizacional, somada a uma maior exigência por parte dos consumidores pela prestação do serviços e oferta de produtos com maior qualidade e eficiência (LEVY, 2010).

Nas organizações públicas, este comportamento dos agentes não é diferente. Os usuários do serviço público, isto é, os cidadãos, demandam, além de qualidade e eficiência nos serviços e produtos públicos ofertados, que estes sejam transparentes, por se tratarem de produtos e serviços essenciais; em contraste, há uma lacuna tecnológica e de modelos eficazes de gestão organizacional presentes entre o setor público e privado (FORTIS, 2009).

É destaque que um dos principais recursos que respondem pela qualidade e eficiência do serviço prestado ao cidadão é o servidor público e o seu uso, por parte das organizações públicas, de maneira estratégica aos objetivos organizacionais (MOTTA, 2013). Ribeiro (2006) ressalta que a Gestão de Pessoas tem como objetivo primordial a administração das relações interpessoais nas organizações, uma vez que as pessoas são, como aponta o autor, consideradas parceiras do empreendimento desenvolvido, e não meros recursos à disposição da organização. A Gestão de Pessoas deve, portanto, voltar-se ao comprometimento e parceria de modo a contribuir para a organização ao alcance de seus objetivos estratégicos por meio das pessoas.

Para que as organizações façam corretamente o uso das capacidades de pessoal, Dutra et al. (2006) aponta ser necessário uma gestão de pessoas, cujos esforços estejam orientados e alinhados estrategicamente com os objetivos da organização, por meio da discussão de competências individuais e organizacionais. Ao se adotar esta noção para o serviço público, não há como desassociar um eficiente alcance dos objetivos das instituições públicas à competência do servidor público.

O estudo da gestão de competências para a gestão de pessoas, iniciado na década de 1970, procura trazer ao trabalhador os conhecimentos, habilidades e aptidões (MCCLELAND, 1973) adequados e desejáveis para uma realidade cujas técnicas e processos de trabalho são específicos em um determinado contexto profissional e social no qual o servidor público, neste caso, está inserido. Neste sentido, a gestão por competências, segundo Santos (2011), dividiu-se em um debate acadêmico acerca do estudo de competências, entre a escola francesa, que possui foco nos atributos do indivíduo, e a escola americana, que centra suas análises nas competências segundo o desempenho organizacional.

Uma das ferramentas para gerir pessoas, entre as que são capazes de desenvolver competências, encontra-se exatamente a elaboração e uso estratégico de planos de carreira (COSTA et al., 2011). Os planos 
de carreira, conforme aponta Costa et al. (2011), são um conjunto de regras institucionais que dispõem sobre as condições, deveres e direitos do trabalhador investido em um cargo ligado ao devido plano. Constituemse elementos interessantes uma vez que planos bem elaborados são capazes de reter, motivar e desenvolver profissionalmente o servidor por meio de uma série de incentivos ao longo de sua carreira profissional na instituição.

A atual estrutura do serviço público brasileiro é muito ampla, contando com uma diversidade de atividades desempenhadas na economia e sociedade também muito amplas (SCHWARTZAM, 2017). Problemas em um planejamento governamental que seja capaz de estabelecer diretrizes mais claras das instâncias máximas para as instâncias inferiores do Poder Judiciário, do Legislativo e, sobretudo, do Executivo acarretam na discrepância entre o desempenho percebido nas mais diversas organizações públicas. Aliado a isto, Dutra et al. (2006) identificaram que muitos dos gestores de grandes empresas, cuja noção pode ser trazida para o serviço público, estão dispersos quanto ao entendimento prático e conceitual de competências, o que pode implicar no desenvolvimento de competências não desejáveis para se atingir os objetivos estratégicos das organizações.

Observando-se todos estes fenômenos pela perspectiva da qualidade das atividades desenvolvidas na educação pública brasileira de nível superior, em 2005, o Ministério da Educação (MEC) implantou outro mecanismo de profissionalização do serviço público: o Plano de Carreira dos Cargos Técnico-Administrativos em Educação (PCCTAE), no âmbito das Instituições Federais de Ensino Superior (IFES) vinculadas ao mesmo. A Lei 11091 de 12 de dezembro de 2005, que dispõe de tal Plano, objetivou reestruturar e modernizar o serviço público nas IFES por meio da preocupação com a capacitação, qualificação e avaliação de desempenho ao longo da carreira de seus servidores. A proposta visa atender os objetivos dos Planos Plurianuais (PPA) e das IFES em âmbito macro e os objetivos dos Planos de Desenvolvimento Institucional (PDI) de cada IFES alinhado com os Planos de desenvolvimento dos Integrantes do Plano de Carreira (PDIPC), no âmbito de cada instituição.

Diante do apresentado, chega-se ao problema de pesquisa: como é o comportamento no desenvolvimento da carreira dos Técnicos Administrativos em Educação, segundo a percepção da alta administração de uma IFES?. Levando-se em consideração os elementos constantes no planos de carreira como uma das ferramentas de políticas públicas que estimulam comportamentos desejáveis de servidores, o presente estudo se preocupa em avaliar o comportamento no desenvolvimento da carreira dos Técnicos Administrativos em Educação a partir da percepção da alta gestão de uma Universidade Federal, sob uma perspectiva de desenvolvimento de competências em consonância com os objetivos estratégicos institucionais.

\section{REVISÃO TEÓRICA}

Para que se atinjam objetivos dentro de uma organização, surge a necessidade da gestão estratégica de pessoas, tal modelo, como aponta Fernandes (2013), objetiva a conversão de estratégias em resultados 
por meio de um plano de ação. O modelo de gestão estabelece as diretrizes que orientarão este plano de ação. Fischer (2002, citado por FLEURY, 2002a) apresenta o conceito de um modelo de gestão de pessoas.

É a maneira pela qual uma empresa se organiza para gerenciar e orientar o comportamento humano no trabalho. Para isso a empresa se estrutura definindo princípios, estratégias, políticas e práticas ou processos de gestão. Tudo o que interfere de alguma maneira nas relações organizacionais pode ser considerado componente do modelo de gestão de pessoas. O comportamento organizacional não é produto direto de um processo de gestão, mas o resultado das relações pessoais, interpessoais e sociais que ocorrem na empresa. Gestão de pessoas é direcionamento e orientação desse agregado de interações humanas.

Diante do conceito detalhado por Fischer (2002, citado por FLEURY, 2002a), percebe-se como o estabelecimento de estratégias específicas determinadas pelas organizações definem um modelo de gestão de pessoas mais adequado para o êxito da Gestão de Pessoas nas organizações públicas. Neste mesmo sentido, Dutra (2004) afirma que um sistema de gestão de pessoas, articulado com as estratégias organizacionais e com as expectativas das pessoas, ganha legitimidade e credibilidade por agregar valor tanto para a organização como um todo, quanto para as pessoas que com ela mantêm relações de trabalho.

Definir o conceito de competências, por se tratar de um constructo que é trabalhado desde a década de 1970 (SANTOS, 2011), implica em analisar diferentes correntes teóricas que tratam do mesmo assunto (COSTA et al., 2011; DUTRA, 2004; FLEURY et al., 2001; BOTERF, 2001; MCCLELLAND, 1973; STEFFEN, 1999, ZARIFIAN, 2008). Fernandes (2013) apresenta sua concepção de competência como "Conjunto de recursos articulados que geram valor para a organização são difíceis de imitar, podem ser transferidos a outras áreas, produtos ou serviços da organização, e impactam o desempenho organizacional em um fator-chave de sucesso".

Segundo Fernandes (2013), o termo "fator-chave de sucesso" deriva da Administração Estratégica e pode ser definido segundo o autor, como elementos essenciais para o sucesso competitivo em determinado setor, o que reforça a ideia da relação próxima entre o constructo competências e competitividade. Quanto à manifestação das competências, a literatura utilizada apresenta que as competências nas organizações podem se manifestar por meio de dois agentes: indivíduo e organização (PAIVA et al., 2001; DUTRA, 2001, 2004; DUTRA et al., 2006; FERNANDES, 2013; FLEURY et al., 2004; BOTERF, 2001; ZARIFIAN, 2008).

Diante da série de conceitos que definem o constructo e que foram aqui apresentadas, considerouse relevante a apresentação dos conceitos de competências individuais e competências organizacionais, a fim de compreender como o processo de ensino e aprendizagem contribui para a formação de competências individuais e competências organizacionais.

Trabalhar o conceito de competências individuais (ou gerenciais) implica na ideia de mobilizar conhecimentos habilidades e atitudes pessoais e profissionais para o cumprimento de objetivos organizacionais (FERNANDES, 2013; RUAS et al., 2010; FLEURY et al., 2001, 2004; DUTRA, 2001, 2004; DUTRA et al., 2006; FERNANDES, 2013; BOTERF, 2001; MOTTA, 2013; ZARIFIAN, 2008).

Fernandes (2013) percebe nas competências individuais uma dupla dimensão, sendo elas as capacidades, que se configuram como pré-requisitos para uma atuação profissional competente e as entregas, que como o autor afirma, são a 'marca' das competências individuais, uma vez que, sustentadas 
pelas capacidades, traduzem na efetiva aplicação profissional das capacidades individuais, atuando como geradoras de valor para a organização e para o próprio indivíduo. $\mathrm{O}$ autor sintetiza muito bem a literatura abordada neste campo e define competências individuais como "um conjunto de conhecimentos, habilidades, atitudes e valores que um indivíduo mobiliza e aplica, de forma reiterada, dentro de um contexto profissional, agregando valor à organização e a si mesmo" (FERNANDES, 2013).

Dutra (2004) define um modelo de gestão por competências como um conjunto de conceitos e práticas para desenvolver, consistentemente, as competências das pessoas e da organização. Existindo para alinhar as contribuições das pessoas aos objetivos do negócio, fazem isso ao estabelecer as competências individuais necessárias às estratégias e desenvolver as pessoas para desenvolver a organização. Para este estudo, entende-se competência como um conjunto de conhecimentos, habilidades, atitudes e valores mobilizados e que resultam em entregas para a organização. Os conceitos de Fleury et al. (2001), Fernandes (2013) e Zarifian (2008) são aqueles que norteiam a noção deste constructo.

Dada a literatura levantada, a competência, portanto, pode ser considerada como um dos elementos presentes na carreira de um trabalhador cujo desenvolvimento é certamente um dos elementos responsáveis pela consecução de objetivos organizacionais (FERNANDES, 2013; RUAS et al., 2010; FLEURY et al., 2001, 2004; DUTRA, 2001, 2004; DUTRA et al., 2006; BOTERF, 2001; MOTTA, 2013; ZARIFIAN, 2008). A gestão das carreiras, para tanto, implica em uma ferramenta que seja capaz de orientar como conhecimentos, habilidades, atitudes e valores se desenvolverão e configurarão em um ambiente profissional. Deste modo, o estudo de carreiras é certamente uma forma de identificar seus respectivos limites e potencialidades quanto ao desenvolvimento profissional individual e organizacional tomando-se por base a noção de competências.

\section{METODOLOGIA}

Quanto aos procedimentos técnicos que norteiam esta pesquisa, quanto à abordagem do problema, conforme Godoy (1995), é uma pesquisa qualitativa, pois o pesquisador não está preocupado em enumerar ou medir os eventos estudados, nem mesmo empregar instrumentos estatísticos para a análise de dados. Sua maior preocupação é a obtenção de dados descritivos sobre pessoas, lugares, processos, entre outros, procurando compreender os fenômenos segundo a perspectiva de cada participante.

Quanto aos objetivos, esta pesquisa pode ser classificada como descritiva, pois, conforme Gil (1988), a pesquisa descritiva procura-se descrever as características de um determinado problema ou fenômeno, por meio de relações entre variáveis que, no caso desta pesquisa, procura descrever a percepção da administração superior em relação à capacitação dos técnicos administrativos e o desenvolvimento de competências.

Portanto, a unidade de análise desta pesquisa é a alta administração de uma IFES, sobretudo, a percepção destes indivíduos. O instrumento de coleta de dados fundamentou-se em um roteiro semiestruturado, utilizado para realizar entrevistas em profundidade, a fim de se obter amplas informações e verificar, segundo percepções de tais gestores, o comportamento do desenvolvimento do técnico administrativo na carreira, bem como as implicações da sua formação para a unidade onde trabalha. 
Enquanto método de análise dos dados coletados por meio da entrevista semiestruturada, foi utilizada a análise de conteúdo. Segundo Bardin (2004), a análise de conteúdo constitui-se como "um conjunto de técnicas de análise das comunicações". A comunicação, elemento-chave desse método de análise de dados, pode ser entendida como a emissão de significados de um emissor para um receptor (BARDIN, 2004). Para Bardin (2004), a análise de conteúdo tem por finalidade na pesquisa: apresentar orientações para uma nova análise e implicação na utilização dos resultados da análise para fins teóricos ou pragmáticos.

Quanto aos critérios de seleção de participantes para a entrevista, foi utilizada uma amostragem, observando-se a alta gestão da universidade que trabalham com as atividades-meio da instituição. A fim de entendimento desse trabalho, a alta administração corresponde aos servidores que ocupam Cargos de Direção - CD de níveis CD-1, CD-2, CD-3 e CD-4, correspondendo, segundo análise de dados, a um total de 94 servidores com CD, segundo dados da unidade responsável pela gestão de pessoas fornecidos em novembro de 2017

Em um universo de 94 gestores da alta administração da universidade, foi utilizado como critério de seleção dos participantes a amostragem por conveniência, de modo que os entrevistados se colocaram prontamente disponíveis para a realização da pesquisa até que se atingisse a dimensão desejada na amostra. Significa dizer que a seleção se caracterizou por meio do contato realizado por meio de correspondência ou telefone com as unidades de trabalho desses gestores, convidando-os para participarem da entrevista, selecionando aqueles que responderem ao contato com prontidão até que se atingisse a saturação dos dados coletados.

Quanto ao tamanho da amostra, utilizaram-se novos participantes até a identificação da saturação dos dados coletados. Segundo Baker et al. (2012), a dimensão de entrevistados em uma pesquisa qualitativa deve ser aquela que seja o suficiente para trazer novas informações que sejam capazes de responder às questões de pesquisa e que atinjam nível de saturação dos dados coletados. Segundo estudo de Baker et al. (2012), o qual consistiu na consulta de diversos profissionais que trabalham com pesquisas qualitativas, a amostragem ideal para entrevistas quando traduzidas para Adler et al. (2012, citado por BACKER et al., 2012), consiste em um montante capaz de fornecer a experiência ao pesquisador de planejar, estruturar entrevistas, conduzir e transcrevê-las e gerar novas informações para a pesquisa.

\section{RESULTADOS}

Durante a realização das entrevistas, ao se traçar um perfil dos 8 entrevistados, evidenciou-se que tais entrevistados possuem alta qualificação e elevado tempo de atuação enquanto gestor. A qualificação dos mesmos configura-se entre o nível de especialização lato sensu até o pós-doutorado, sendo a maioria dos entrevistados qualificados como doutores. Com uma média de quase 18 anos de atuação na área de gestão da instituição, resultante do somatório da ocupação no cargo atual e em cargos anteriores, pôde-se verificar como tais entrevistados estão imbuídos de experiência ao se levar em consideração o tempo de experiência em gestão. 
Com o intuito de atingir o objetivo deste estudo, em primeiro lugar, verificou-se que o significado de competências, na visão dos entrevistados, está associado a mobilização das capacidades e entregas, indo ao encontro do conceito teórico adotado para este estudo. A análise de conteúdo utilizada para compreender o conceito de competências segundo a percepção dos gestores está dividida nas categorias: atitudes, conhecimentos, habilidades e valores aqui divididos conforme conceitos de Fleury et al. (2001), Fernandes (2013) e Zarifian (2008). Dentro das categorias divididas, foram codificados elementos nos relatos dos entrevistados que os adequassem a uma das categorias conforme tabela 1.

Tabela 1 - Significado de competência segundo os gestores entrevistados.

\begin{tabular}{|l|c|c|}
\hline & $\mathbf{N}^{*}$ & \\
\hline Atitudes & $\mathbf{1 3}$ & Valores \\
\hline Comprometimento & 5 & Interesse pelo Trabalho Desenvolvido \\
\hline Saber trabalhar em grupo & 3 & Inteligência Emocional \\
\hline Visão Crítica & 2 & Empatia \\
\hline Resiliência Individual & 2 & \\
\hline Prontidão & 1 & \\
\hline Conhecimentos & $\mathbf{8}$ & Habilidades \\
\hline Conhecimento Técnico da Atividade & 4 & Comunicar em Língua Estrangeira \\
\hline Elemento Cognitivo & 3 & Domínio de Ferramentas de Informática \\
\hline Conhecimento Institucional & 1 & \\
\hline
\end{tabular}

Legenda: * um mesmo entrevistado pode mencionar mais de um elemento codificado.

De um total de 30 códigos selecionados para a compreensão da noção de competências pelos gestores, encontrou-se que 19 deles (63,3\% do total de códigos) são elementos pertencentes às denominadas competências sociais (valores e atitudes) de Zarifian (2008) e Fernandes (2013), que orientam o comportamento organizacional do trabalhador. Este resultado demonstra, para os entrevistados, como a competência está mais relacionada ao comportamento emocional e as atitudes que derivam de tais emoções do que ao conhecimento e às habilidades utilizadas no trabalho.

Para a categoria atitude, que se refere ao comportamento habitual do indivíduo orientado por valores, crenças e propósitos, observou-se que o código comprometimento, fora o mais mencionado, correspondendo a 5 dos 8 entrevistados. Segundo os entrevistados, tal conceito se concentra na capacidade do servidor de se envolver no trabalho desenvolvido, bem como na instituição a qual o servidor está inserido até a conclusão de um processo. A crítica não está na falta de capacitação e qualificação, oriunda do processo de aprendizado, mas na falta de mobilização do conhecimento e das habilidades do servidor devido à falta de interesse do servidor ou à falta de ações do gestor com seus subordinados. O trecho a seguir relata a opinião de um dos entrevistados acerca do conceito de competência relacionado ao comprometimento.

(...) é o famoso CHA. Competências ou conhecimentos, habilidades e atitudes. Os conhecimentos e habilidades, são muito bons hoje, o que não quer dizer que a atitude é boa. Então pessoas com alta formação muitas vezes não desempenham bem seu papel porque não querem. Atitude é o comprometimento, porque a pessoa tem que saber, poder e querer. Ela sabe, pode e muitas vezes não quer. Nós temos gente aí com, mesmo doutorado, não tem envolvimento no trabalho, faz o que é mandado, ou não. (Entrevistado 7)

O código saber trabalhar em grupo fora mencionado por 3 dos 8 entrevistados e para os entrevistados, tal competência reflete na capacidade do TAE em ouvir os colegas de trabalho e saber tomar decisões em colegiado. Além disto fora relatada a dificuldade de comunicação entre técnicos de unidades 
administrativas ou acadêmicas distintas, para tal, um técnico que consegue alinhar o trabalho com técnicos fora de sua unidade de trabalho é de grande competência para a instituição, conforme relato.

(...) nós temos que ter um trato profissional, ou seja, se é um trato profissional, se está relacionado, se a minha atividade impacta na sua e a sua atividade impacta na minha, nós temos que minimante alinhar procedimentos, alinhar falas, alinhar sugestões. Eu não posso simplesmente me omitir diante dessa ou dessas situações. (Entrevistado 4)

A segunda categoria mais encontrada na definição de competência pelos entrevistados fora a de conhecimentos. Com 8 referências à esta categoria, encontrou-se que a competência no serviço público possui conceito associado ao nível de conhecimento técnico da atividade desempenhada, como um elemento cognitivo e, por último, relacionado ao conhecimento institucional.

O primeiro código, que se relaciona ao conhecimento técnico da atividade desenvolvida fora encontrado em 4 dos 8 entrevistados, para eles o conhecimento deve ser direcionado, ou seja, deve estar alinhado à área de atuação, para que haja retorno profissional. Tal menção mostra a clareza que 4 destes 8 entrevistados possuem acerca da necessidade de os conhecimentos causarem mobilização e resultados para a organização, conforme apontado nos estudos de Ferreira (2013). Em uma das entrevistas, encontrou-se que os conhecimentos técnicos alinhados à área de atuação proporcionam um trato mais aprofundado, por parte do TAE, de elementos relacionados ao seu trabalho.

Competência da área de atuação, ou referência, é fundamental, por exemplo, não adianta eu organizar bem processos, não adianta eu conhecer bem de planilhas, são questões instrumentais, não adianta eu ter equilíbrio emocional apenas, não adianta eu saber me posicionar no coletivo se a gente não conhece da área da qual nós trabalhamos. Há de se ter conhecimentos e habilidades para discutir o que é (área de trabalho do entrevistado), o limite da (área de trabalho do entrevistado), os indicadores da (área de trabalho do entrevistado), coisas dessa natureza. (Entrevistado 5)

Enquanto elemento cognitivo, 3 dos 8 entrevistados associaram o conceito de competências como um processo mais generalizado, resultante do aprendizado, da observação, memória, juízo e raciocínio. 0 conceito de Perrenoud (1999) aponta a cognição como um elemento característico do conceito de competência, sobretudo na área da educação. Porém, para Perrenoud (1999), o próprio processo cognitivo relaciona-se não somente com o desenvolvimento de conhecimentos como capaz de desenvolver habilidades, haja vista a presença de processos intuitivos, de observação, reflexão oriundos do processo de aprendizagem que induzirão um indivíduo a uma ação mais apropriada. $\mathrm{O}$ trecho a seguir, que trata da definição de competências por um dos entrevistados, demonstra como este conceito está bem alinhado à compreensão deste eixo teórico pelo entrevistado.

Competência, ela é uma competência cognitiva, porque eu posso trabalhar com ela, as pessoas têm uma formação para tal, para uma determinada função, elas se preparam para isso, ou elas adquirem essa competência no desenvolvimento da atividade, ou seja, ela desenvolve uma habilidade em relação a procedimento, que permite a esse servidor uma resposta mais rápida as demandas feitas a ele. Para que haja maior competência, eu tenho que capacitar o servidor naquela função que ele exerce. (Entrevistado 4)

O código conhecimento institucional trata de um problema de ordem prática no serviço público. 0 que se escuta comumente é a crítica na universidade sobre a falta de preparo dos técnicos em direcionar o usuário de seu serviço para atividades que estão fora do seu campo de atuação. O ponto central aqui mencionado trata da necessidade dos TAE de possuírem um nível de conhecimento institucional necessário 
que seja capaz de direcionarem corretamente o cidadão para a unidade que atenda corretamente a sua demanda, de forma a não causar o desgaste no cidadão de procurar vagamente pela solução de seu problema. Um dos entrevistados teve esta preocupação e alegou sofrer muito com este problema tanto na universidade de análise quanto em outras IFES alegando este ser um elemento muito importante na configuração de competência no serviço público prestado.

Respostas objetivas e respostas indicativas, ou seja, se não é do setor dele, ele saber e conhecer a instituição para que ele assim, uma coisa que eu sempre falo para os meus servidores que o maior constrangimento que eu passo, às vezes, não na universidade, em outras instituições, é quando eu preciso de uma indicação de um setor, eu chego no setor e o setor fala eu nem sei o que é isso. Então, primeiramente, é conhecer a instituição. (Entrevistado 4)

A categoria valores fora mencionada 6 vezes, relatando pelos entrevistados como tais elementos são importantes haja vista que são balizadores do comportamento dos indivíduos em seu local de trabalho. Os códigos encontrados foram: interesse pelo trabalho, inteligência emocional e empatia. Como os valores orientam as atitudes, o interesse pelo trabalho, mencionado por 3 dos 8 entrevistados, aparece aqui como um agente mobilizador da atitude comprometimento e visão crítica, conforme transcrição da entrevista, em que o entrevistado aponta a necessidade de ter afeição por aquilo que se faz.

Aqui dentro você tem que ter um tipo 'vestir a camisa' mesmo, porque hoje a universidade, no início, quando nós começamos, o quantitativo de servidores que a gente atendia era 1/3, mais ou menos, do que se tem hoje. E como a gente não consegue ter uma substituição de todos os servidores, você continua fazendo o mesmo serviço, com o mesmo quantitativo de pessoas, com um público muito maior do que antes. Nessa competência do conhecimento você tem que 'vestir a camisa', porque senão você não consegue fazer. Se você não tiver amor no que você faz, você vai ser um mero digitador, e aqui dentro, para nós, não serve ser um mero digitador... Se nós não tivermos pessoas engajadas no trabalho que a gente faz, a gente não consegue fazer, não consegue executar. Tem que ter conhecimento e engajamento sim do que você vai fazer aqui dentro. (Entrevistado 1)

Já o código 'inteligência emocional' demonstrou a necessidade de os servidores no serviço possuírem autoconhecimento emocional, a fim de que controlem suas emoções para não agirem por impulso ou terem uma reação inadequada à determinadas circunstâncias do trabalho. Quando questionado, o conceito de competência para um dos entrevistados descreve bem tal código. Afirma, o Entrevistado 8, que 'Pessoas competentes são pessoas que são emocionalmente inteligentes, que são equilibradas emocionalmente, isso é fundamental também nesse processo. Acho que isso, e ali sempre tendo senso de responsabilidade presente. Basicamente seria isso'.

Já o último código, relacionado a 'valores fora a empatia', para o Entrevistado 7, o termo competência no serviço público está associado à noção de comunidade por parte do servidor público. Ele afirma que 'O perfil profissional é a pessoa que tenha um sentido público de comunidade, ou seja, eu vim para servir ao público'.

A categoria 'habilidades' fora a que menos se encontrou enquanto definidora do conceito de competências, encontrada em 3 momentos da análise dos dados. Contudo, foram levantadas habilidades pelos entrevistados que segundo eles, são ímpares para a execução das atividades na universidade, bem como o seu desenvolvimento e expansão, sendo elas: domínio de língua estrangeira e o domínio da informática pelos servidores públicos. 
Para melhor entendimento da noção de competências, segundo a percepção da alta gestão da universidade, fora questionado aos entrevistados qual a principal consequência de se trabalhar com um grupo de servidores cujas competências estão desenvolvidas e os resultados encontrados estão dispostos na tabela 2.

Tabela 2: Consequências das competências desenvolvidas segundo os gestores entrevistados.

\begin{tabular}{|l|c|}
\hline & $\mathbf{N}^{*}$ \\
\hline Consequências & $\mathbf{8}$ \\
\hline Maior Eficiência na execução das atividades & 4 \\
\hline Melhor Relacionamento Interpessoal & 2 \\
\hline Resposta para a Sociedade & 2 \\
\hline
\end{tabular}

Dos resultados encontrados, 4 dos respondentes afirmaram que a consequência do servidor público competente é uma maior eficiência na execução das atividades. Um dos entrevistados afirmou que a competência é responsável por agir como um elemento mitigador de elementos negativos oriundos do serviço público. Para tal, um trabalho inerentemente desenvolvido por pessoas competentes tende a possuir uma redução nos erros, segundo dois dos entrevistados, de modo a trazer menos prejuízos para a equipe e para a União. Um elemento que chamou a atenção fora a resposta de um dos entrevistados, no qual ele aponta uma maior fluidez nos trâmites processuais, aqui codificado como maior eficiência na execução das atividades. O trecho da entrevista está transcrito.

A fluidez na ação profissional. O que ocorre muito no serviço público é que os processos travam dentro da área que viabiliza por falta de conhecimentos e competências nesses campos. Ai a gente tem que administrar conflitos por falta de competência socioemocional, a gente tem que resolver problemas técnicos por falta de competência instrumental e técnica, a gente tem que resolver problemas de má orientação por falta de competências de referência. Isso trava o processo e não permite o cumprimento do objeto da (unidade de trabalho do entrevistado). Então quando você me pergunta: Qual é o impacto de pessoas que têm minimamente tais competências?. Os processos são mais fluidos e a segurança na orientação, na execução, no planejamento e na avaliação dos processos. (Entrevistado 5)

Outro elemento encontrado na pesquisa corresponde a um melhor relacionamento interpessoal. Segundo 2 dos entrevistados, a competência, aqui entendida como as competências sociais (atitudes e valores), são responsáveis por conduzir a uma melhoria no relacionamento interpessoal. Um dos entrevistados afirmou explorar o desenvolvimento de competências que tornem os TAE capazes de participarem do processo de tomada de decisões em sua unidade de trabalho por meio do planejamento e abertura de espaço para opinarem a respeito das medidas de gestão adotadas pelo entrevistado.

Sendo assim, o relacionamento interpessoal da equipe acabou por unificar a equipe e deu abertura a um espaço adequado para a resolução de conflitos e tomada de decisões. O entrevistado 3 afirma que 'A unificação, a integração das equipes, nós estamos percebendo uma, a satisfação dos servidores, porque eles se sentem muito mais empoderados, eles se sentem atuantes na (unidade de trabalho do entrevistado), sentem que estão de fato participando das ações'.

Por último, dois dos entrevistados indicaram que a maior consequência de se ter uma equipe competente traduz-se na resposta para a sociedade quanto aos serviços ofertados. Não adianta somente um dos servidores ser competente, haja vista a complexidade de unidades em que tramitam os processos nas diversas unidades organizacionais, desta maneira há de se perceber que a equipe quando atuante de forma 
competente, traz as competências organizacionais que são, de fato, as responsáveis pela consecução dos objetivos a nível de planejamento institucional, conforme havia traduzido Fernandes (2013), correspondendo ao nível de prontidão em que determinada organização possui para implantar suas estratégias, logo, podendo compreender como a capacidade também de atingir os objetivos.

Sendo assim, capaz de agregar valor, conforme apontado nos estudos de Dutra (2004), haja vista que ser uma instituição pública cujos servidores públicos desenvolvem seu trabalho com competência, acaba por agregar valor só como instituição capaz de desenvolver serviços com seriedade e qualidade para a população. A transcrição do trecho da entrevista faz menção a um dos relatos relacionado à resposta para a sociedade.

Resposta para a sociedade. É isso que eu chamo de consequência da competência, é isso que eu chamo de racionalidade, porque, as vezes você está fazendo a sua atribuição, você está cumprindo com sua atribuição, só que chega num outro lado, no outro lado do balcão, vamos chamar assim, a coisa não flui. Mas não flui por quê? A pessoa entendeu o que você fez? Ela sabe o que você quer? Ali fica parado e não chega aonde necessariamente teria que chegar, que é a última instância: a sociedade. (Entrevistado 4)

Percebe-se, a partir dos dados coletados, como a competência no serviço público é, de fato, um recurso estratégico para a boa consecução das atividades oferecidas em qualquer órgão ou unidade pública e que de fato é responsável por formar a opinião pública a respeito da qualidade do serviço público prestado. Não adianta que o serviço seja prestado com qualidade por apenas uma parte do corpo técnico ou docente de uma instituição federal de ensino. Essa característica deve ser homogênea.

\section{DISCUSSÃO}

Questionou-se aos entrevistados se técnicos que estão mais progredidos na carreira, isto é, progredidos por mérito e por capacitação, possuem desempenho profissional melhor do que aqueles que estão no início da carreira. As respostas foram consenso entre os entrevistados: não necessariamente. Primeiramente, ao se levar em consideração os cursos de capacitação para progressão por capacitação, um dos entrevistados mencionou a necessidade dos cursos desenvolverem melhor o trabalho do TAE a fim de que, conforme Fleury et al. (2001), estejam relacionados com as necessidades e objetivos da organização, aqui especificamente, da unidade administrativa ao qual o técnico está em exercício.

Não necessariamente. $O$ que eu quero dizer é que a progressão por capacitação, ele te leva a um patamar orçamentário melhor, mas isso não significa que você tendo alcançado aquela progressão, você desenvolve melhor o seu trabalho, não é condição sine qua non. Se a titulação não se estreitar com a área de atuação, não necessariamente ela (a pessoa) terá uma diferenciação, terá um diferencial só porque terá cursos em seu currículo. (Entrevistado 5)

Conforme relato do entrevistado, para que haja uma melhoria de desempenho, o conhecimento deve ser direcionado para as necessidades eventuais da unidade organizacional. De nada adianta a obtenção de novos conhecimentos via capacitação se aqueles conhecimentos não serão úteis para a unidade organizacional. Conforme aponta Fernandes (2013), é importante que tais competências desenvolvidas estejam caracterizadas como entregas, ou seja devem apresentar claramente o valor agregado para a instituição. 
Outra crítica relacionada à progressão por capacitação se encontra no fato de não haver um modelo de gestão por competências que faça o levantamento de necessidades de capacitação e aperfeiçoamento, seguido do monitoramento com o intuito de verificar se tais necessidades foram totais ou parcialmente atendidas. Na atual configuração, o próprio servidor é o responsável por gerir os cursos de capacitação que serão necessários para a sua própria progressão. Não há um acompanhamento da chefia a fim de verificar se, de fato, tal curso irá agregar valor para a unidade. Tal fenômeno é mencionado em trecho transcrito em uma das entrevistas.

(...) é necessário um maior envolvimento dos próprios gestores na identificação dos elementos formativos de sua equipe. Eu quero dizer, será que a formação oferecida pela DICAP corresponde necessariamente uma demanda do serviço, a demanda do trabalho daquele servidor? Outro ponto, como servidor planeja o seu próprio processo de formação? E como esse servidor indica e aponta a sua própria deficiência formativa para atuação profissional para elaboração de um plano institucional de formação? (...) Capazes, todos somos, temos capacidade de realizar. (Entrevistado 6)

Em segundo lugar, a progressão por desempenho ou mérito dos técnicos fora vista de forma semelhante pelos entrevistados, haja vista problemas identificados pelas chefias tanto no instrumento avaliativo quanto no próprio processo de avaliação, por parte dos avaliadores. Para os entrevistados, não necessariamente a progressão por mérito impacta no desenvolvimento profissional dos técnicos da mesma forma que servidores mais progredidos não necessariamente podem ter um desempenho profissional melhor que os menos progredidos na carreira. O trecho transcrito, em entrevista realizada com um dos gestores, identifica um oportunismo por parte dos servidores avaliados.

Da forma que estava as perguntas eram totalmente amplas de mais, muito difícil de você justificar uma notai inferior e eu via muito oportunismo também. O que eu estou chamando de oportunismo? Chegava próximo do gestor fazer o desempenho do servidor, e aí tinha lá, isso acontecia de mais comigo, tinha uma parte lá que, o servidor cuida dos equipamentos, cuida do patrimônio. Eu via alguns servidores, duas, três semanas antes ia lá, limpava o computador, limpava impressora, limava não sei o que, limpava não sei o que lá. Aí você chegava na hora de fazer o desempenho, você respondendo aqui, se você colocar uma nota baixa, a pessoas, mas eu limpei tudo aqui, está tudo organizado, porque você está colocando essa nota baixa. A meu ver as perguntas que estavam não impactavam diretamente em uma melhor qualidade ou em um melhor desempenho dos funcionários naquele momento. Ao mesmo tempo, uma nota muito baixa criava um desconforto para a pessoa, de uma certa forma parece que ela acordava, você fala, opa, espera, o que será que está acontecendo para que eu tirasse essa nota, tinha um certo desconforto ali. A nota de uma certa forma fazia com que o funcionário percebesse algumas questões que talvez ele não estivesse percebendo. (Entrevistado 3)

Foi identificado durante as entrevistas que existe um problema gerencial, ao qual a chefia procura evitar conflitos e se indispõe a penalizar um servidor ao realizar uma avaliação fidedigna com o desempenho do servidor pela relação pessoal construída ao longo do tempo, o chamado 'coleguismo'. O trecho transcrito demonstra exatamente este ponto encontrado por outro dos entrevistados e sugere a participação de um número maior de agentes no processo avaliativo do servidor, como uma espécie de avaliação 360 graus.

Se a gente tivesse condições de ter pessoas fora que viessem fazer uma avaliação do serviço da pessoa eu acho que seria melhor, porque a medida do, enquanto eu estou fazendo, eu chefe, com servidor ou colega de trabalho, a gente fica com sentimento de coleguismo. Se eu der uma nota ruim para aquele servidor, eu sei de todas as dificuldades financeiras que a gente passa, não vai ser eu a prejudicar, para não deixar aquela pessoa ter uma progressão. Isso, se você conversar com várias pessoas, isso é um sentimento muito forte. 
E para quebrar certos paradigmas, a gente tem que ter muita conversa, muita preparação, que eu acho que nós, dirigentes, falando até por mim, as vezes eu não tenho essa preparação de fazer uma avaliação não tão boa do servidor. (Entrevistado 1)

Os problemas elencados pelo gestor refletem um despreparo da chefia para assumir e resolver conflitos e aplicar uma avaliação adequada para o comportamento do servidor. A chefia não pretende ser o agente responsável por penalizar financeiramente o servidor. Percebe-se aqui a preocupação da chefia não em corrigir os problemas enfrentados no trabalho por meio da avaliação de desempenho, mas sim, em não prejudicar financeiramente o servidor. O caráter mais importante visto até mesmo no discurso da chefia deixa claro o elemento financeiro como prioritário.

Partindo-se para a análise do incentivo a qualificação dos servidores, questionou-se aos gestores se um servidor que tenha uma qualificação superior possui um desempenho profissional além daquele servidor que tenha uma qualificação inferior. Semelhante à progressão por mérito, encontrou-se em quase todas as respostas dos entrevistados a visão de que não necessariamente esta qualificação resulta em aumento de desempenho.

Mais uma vez, o ponto central está no desenvolvimento da qualificação, ficando centrado na relação entre atividade desenvolvida pelo servidor, necessidade de formação da unidade administrativa ou acadêmica e tipologia do curso formal realizado. $O$ trecho transcrito em entrevista demonstra a necessidade encontrada pelo gestor bem como a disponibilidade da chefia em liberar o servidor para se capacitar e qualificar desde que atendam tais pontos.

Não necessariamente, que nós pudéssemos ter as pessoas fazendo os seus cursos de qualificação com impacto direto naquilo que você desenvolve, porque a grande questão hoje é que nós damos um incentivo a qualificação, mesmo que indireto, mas para cursos que foram feitos talvez para cumprir, para simplesmente cumprir uma tabela, para simplesmente dar uma possiblidade de avançar na carreira, Agora, quais daqueles (cursos formais), de fato, seriam fundamentais para a gente fazer. O que seria ideal, ter o planejamento da necessidade de cada um. Olha, ninguém vai te impedir de capacitar, ninguém vai te impedir de qualificar, mas você vai qualificar numa linha que, de fato, possa ser utilizada naquilo que nós precisamos. (Entrevistado 8)

Pode-se entender que o conhecimento, para ser mobilizado, conforme aponta Dutra (2004), precisa impactar em entregas à organização e, logo, em resultados. A necessidade do processo de aprendizado que resulte em conhecimentos alinhados e aplicáveis ao ambiente de trabalho traduz-se na mobilização dos conhecimentos de Fleury et al. (2001), Dutra (2004) e Fernandes (2013).

Quanto ao impedimento de processos de qualificação, fora questionado se as chefias se dispõem a conceder licenças para o servidor se capacitar e qualificar. De tais instrumentos tem-se a licença capacitação, prevista no art.87 da Lei 8.112 de 10 de dezembro de 1990, disponível a cada quinquênio de efetivo exercício, permite ao servidor afastar-se do exercício do cargo, com remuneração, para realizar cursos de capacitação profissional.

Outro instrumento se refere ao afastamento parcial e integral para cursar pós-graduação stricto sensu aos TAE, disposto pelo art. 96 da Lei 8112 de 10 de dezembro de 1990 e com diretrizes estabelecidas no Decreto 5.707 de 23 de fevereiro de 2006. Para tais licenças é necessária a anuência da chefia e fora questionado quais são os critérios adotados pela chefia para concessão de tais licenças ao servidor. $O$ trecho 
transcrito a seguir, demonstra o contexto na qual uma das chefias entrevistadas se depara neste processo de pedido de licenças e afastamentos.

(...) afastamento para capacitação, aquele afastamento de três meses. A gente está recebendo alguns pedidos que nos colocam também numa situação bem complicada, porque um servidor que trabalha com $X$ e quer sair para capacitar $Y$, que não tem nenhuma funcionalidade nem para o setor, nem para ele naquele momento, que a gente percebe isso muito claramente, mas se a gestão nega fica parecendo que é uma perseguição, que a gestão não está contribuindo, não está auxiliando, não está ajudando. Hoje nós estamos em um empasse muito grande. A nossa tentativa é sempre liberar. (...) Só que nos deixa em uma situação bem complexa, porque nós temos um número de servidores restrito, muito pequeno. A saída de um servidor prejudica não só o setor, mas prejudica os outros servidores, porque eles acabam tendo que inserir em suas rotinas as atividades daquele que afastou. E a gente vendo claramente que o pedido não tem nenhuma relação com sua atividade diária, nem com seu cargo, nem com a sua função, e muitas vezes meramente econômico e oportuno na saída de três meses (...) outro problema para a concessão de licenças está no fato técnico não ter direito a um substituto. Eu acho que isso inviabiliza, às vezes, setores com poucos servidores onde a saída de um específico gera uma sobrecarga dos demais servidores, então eu vejo que assim como a carreira de docente você tem um substituto, o técnico poderia trabalhar para se ter algo parecido ou algo próximo a isso. (Entrevistado 3)

O trecho descrito demonstra o impasse em que a chefia se depara ao negar o pedido de licença ou afastamento do servidor para realizar cursos formais que muitas vezes nada têm a contribuir para a execução das atividades desenvolvidas na carreira. Além disto, ilustra a dificuldade em liberar para capacitação e qualificação aqueles servidores cujos cursos de aperfeiçoamento são interessantes para a unidade.

O gestor entrevistado aponta a dificuldade por ter um quadro reduzido de pessoal, primeiro por sobrecarregar os demais servidores TAE que deverão suprir as atividades desenvolvidas por aquele servidor que está com afastamento ou de licença além da ausência de um técnico substituto no serviço público. O servidor substituto é um recurso presente na carreira dos docentes das IFES de todo o Brasil e que tem a principal finalidade de ocupar o quadro de docentes no momento que algum docente efetivo se encontra afastado para realizar cursos de pós-graduação.

Outro ponto remete à ausência da ascensão funcional na carreira, instrumento que era previsto e permitido no plano de carreira anterior e que fora removido com a implantação do PCCTAE. Um dos problemas de se trabalhar com incentivo à qualificação no serviço público é que o servidor muitas vezes poderá ser mais qualificado para desempenhar sua tarefa, porém o nível de complexidade de suas atividades permanece, o que pode gerar certa frustração ao servidor, à medida que seu trabalho se torna cada vez mais simples. Os relatos transcritos demonstram exatamente este cenário.

Eu acho que a qualificação hoje ela torna eclético, ela facilita a comunicação, diálogo, porém hoje nós temos uma série de pessoas com qualificação de nível superior ocupando cargo de nível médio, porque as pessoas vêm, fazem o concurso para aquele nível, que é o que está tendo oportunidade naquela ocasião. Hoje nem tanto, mas houve uma época que quando o sujeito fazia isso, tão logo ele era empossado, ele já queria fazer a sua ascensão para o nível adequado, o que não é possível, a gente sabe que não é possível. Um servidor que faz um concurso para o nível $D$, sempre será nível $D$. A não ser que ele faça outro, mesmo tendo qualificação para nível $E$. Houve uma época dentro da universidade, eu lembro, tinha sempre umas tensões, porque o fulano: Mas eu sou do nível $E$, eu estou no nível $D$, Mas você foi concursado, você admitiu fazer um concurso para o nível D. Agora você não quer permanecer no nível $D$ ? A carreira não permite. Você tem que fazer novo concurso. Nesse sentido, eu não vejo muita diferença de desempenho, não. (Entrevistado 2) 
Porque um doutor vai ser melhor de quem tem segundo grau completo? Talvez não, porque ele vai fazer atividades que nada tem a ver com o alto grau de conhecimento dele, e aí ele se desmotiva. (Entrevistado 7)

Os estudos de Souza (2004), Pires (2005), Lima (2016) centram exatamente na peculiaridade dos planos de carreira no serviço público. Percebe-se, nos estudos de Lima (2016), como a ausência de ascensão funcional na carreira torna de fato os mecanismos como um plano que rigorosamente, retribui financeiramente a requisitos não tão bem observados, em que se despreza a análise de desempenho em outras questões, conforme apontado por Souza (2004), como a capacidade de liderança e multidisciplinariedade das tarefas.

Após tais análises, pôde-se verificar dois problemas que estão relacionados ao objeto de estudo deste trabalho: problemas estruturais do PCCTAE e problemas de gestão quanto ao desenvolvimento de competências por parte dos técnicos, alinhadas aos objetivos estratégicos da instituição. No primeiro, percebe-se o caráter fortemente financeiro dos instrumentos de progressão e qualificação na carreira visto pelos gestores, haja vista as dificuldades aqui apresentadas para a utilização do plano de carreira com eficiência quanto ao desenvolvimento de competências desejáveis. O segundo, relativo a questões gerenciais, que demonstram a necessidade de capacitação, também dos gestores, para orientarem o desenvolvimento de competências adequadas às necessidades das unidades que são responsáveis.

Em suma, as competências analisadas neste estudo não são devidamente exploradas pelos mecanismos e recursos dispostos pelo PCCTAE a fim de se explorar ao máximo o desempenho de um servidor público, seja pelo próprio plano de desenvolvimento, seja pelo plano de desenvolvimento desenvolvido em conjunto com os gestores. O servidor, além dos problemas aqui explorados, quanto à natureza dos cursos e das atividades desempenhadas no seu ambiente profissional, há de se levar em conta que aquele TAE cujo desempenho está 'fora da curva' não terá a sua progressão na carreira acelerada, em comparação aos demais servidores que possuem desempenho 'dentro da curva', também encontrado nos estudos de Lima (2016). Chama-se atenção ao trecho transcrito a seguir em que um dos entrevistados traz tais elementos para discussão com a seguinte observação.

Eu acho que o sistema federal é errado (os planos de carreira do governo federal), ele não privilegia a competência, não é isso. Vamos dizer melhor, não privilegia, a produtividade. É. A carreira é muito baseada das titulações. E aí, se o fulano está desempenhando bem ou não, o nível salarial dele é aquele. Eu acho que isso aí não é um bom estímulo, mas é o sistema que a gente tem... Eu acho que tinha que ser um misto, tinha que ter a qualificação, o título de doutor para prestar concurso, agora se ele apresentar, dentro de critérios estabelecidos pela instituição, produtividade acima dos outros, ele precisava ter um mecanismo de aceleração de progressão para diferenciá-lo dos demais. (Entrevistado 2)

Conforme explorado nos estudos de Hall (1986) e McDonald et al. (2004), identifica-se o PCCTAE, portanto, como um plano de carreira tradicional, cujo reconhecimento pelo desempenho profissional 'fora da curva' possui agravantes ao passo que não permite ao servidor TAE a aceleração da sua progressão, além de ter dificuldades em identificar e reconhecer dentro da carreira aquele técnico que desempenha seu papel profissional com excelência. 


\section{CONCLUSÕES}

Levando-se em consideração os objetivos geral e específicos deste estudo, compreende-se que tais objetivos foram alcançados e devidamente abordados neste estudo. Retomando o objetivo do presente estudo que se traduz em avaliar o comportamento no desenvolvimento da carreira dos Técnicos Administrativos em Educação a partir da percepção da alta gestão de uma Universidade Federal, sob a perspectiva de desenvolvimento de competências em consonância com os objetivos estratégicos institucionais, entende-se que este objetivo tenha sido alcançado.

Quanto à noção de competência no serviço público, os resultados apontaram que a percepção de competência pelos gestores está fortemente associada às competências socioemocionais, que englobam atitudes e valores, apontando elementos como comprometimento e capacidade de trabalho em grupo como essenciais. Foram também levantados os conhecimentos técnicos alinhados às atividades desenvolvidas como importantes elementos na definição da competência no serviço público. Segundo a visão dos entrevistados, as consequências da competência no serviço público resultam em melhor relacionamento interpessoal, maior eficiência na execução das atividades e resposta para a sociedade.

A percepção é de que os elementos de progressão na carreira presentes no PCCTAE são inclinados para objetivos financeiros, os resultados apontam casos com ausência de coesão entre o desenvolvimento profissional e a geração de competências individuais e organizacionais através da progressão na carreira. Encontrou-se que as avaliações de desempenho não estão alinhadas, de fato, ao desempenho profissional do servidor, as chefias, por se sentirem desconfortáveis em penalizar financeiramente um servidor, acabam por realizar avaliações que não são condizentes ao desempenho do servidor.

Quanto às possibilidades de aperfeiçoamento profissional por meio de cursos de capacitação e qualificação, foram encontradas críticas da alta administração a respeito da incompatibilidade dos cursos realizados em relação às atividades profissionais desenvolvidas no exercício do cargo. Já para os casos de concessões de licenças aos técnicos, as dificuldades relativas ao número restrito de servidores nas unidades administrativas, bem como da ausência de elementos que garantam a contratação temporária de servidores substitutos se destacam como fatores que atuam em detrimento ao desenvolvimento profissional dos TAE.

Verificou-se que a universidade federal analisada carece de políticas de acompanhamento do desenvolvimento profissional voltadas para seu quadro técnico e alinhadas ao planejamento institucional. Esta carência resulta no comportamento dos servidores TAE na carreira de modo autônomo quanto ao levantamento de suas próprias necessidades de aperfeiçoamento e desenvolvimento e definição de como e em que medida serão realizadas as ações de capacitação e qualificação na sua carreira.

Quanto às limitações desta pesquisa, as unidades administrativas responsáveis pela Capacitação e Avaliação de Desempenho da Universidade não foram objetos de análise desta pesquisa. Acredita-se que a coleta de dados nestas unidades, certamente agregariam maiores informações aos resultados desta pesquisa. Sugere-se a aplicação da metodologia utilizada neste estudo em outras IFES, a fim de verificar a existência de pontos contrastantes e pontos em comum com os resultados encontrados. 
No âmbito da elaboração de políticas públicas, os resultados aqui encontrados podem permitir aos agentes formuladores de políticas públicas, sobretudo de Planos de Carreira, melhor elaboração de políticas mais efetivas à qualidade e ao desenvolvimento do serviço público prestado, observando-se os elementos de formação e desenvolvimento profissional dos TAE.

Já no âmbito das IFES, os resultados encontrados a respeito das dificuldades dos gestores ao avaliarem sua equipe de TAE, demonstram a necessidade tanto de capacitação gerencial quanto de mudança da cultura organizacional, de modo a trazer avaliações congruentes com o desempenho profissional dos servidores. Além disto, demonstram a necessidade de políticas mais robustas voltadas ao desenvolvimento e aperfeiçoamento de sua equipe técnica de forma a eliminar do próprio TAE, a autonomia e responsabilidade em definir sozinhos suas eventuais necessidades de formação profissional e assim mitigar situações de servidores que não procuram desenvolver competências ou mesmo o desenvolvimento de competências que não estejam alinhadas com as necessidades institucionais.

Espera-se que este estudo contribua com o debate quanto ao desenvolvimento profissional de servidores públicos, sobretudo nas carreiras das IFES. Ressalta-se a importância de planos de carreira como o PCCTAE, enquanto plano de carreira, haja vista que a adequada utilização dos elementos presentes pode ser responsável por ganhos à qualidade do ensino nas IFES e, sobretudo, à sociedade.

\section{REFERÊNCIAS}

ADLER, P.; ADLER, P.. In: BAKER, S. E.; EDWARDS, R.. How many qualitative interviews is enough?: Expert voices and early career reflections on sampling and cases in qualitative research. Southampton: 2012.

BAKER, S. S.; EDWARDS, R.. How many qualitative interviews is enough?: Expert voices and early career reflections on sampling and cases in qualitative research. Monografia (Graduação) - University of Southampton, Southampton, 2012.

BARDIN, L.. Análise de conteúdo. Lisboa: Edições 70, 2009.

BARRETO, L. M. T. B.. Estratégias de gestão de pessoas e desempenho organizacional na hotelaria: o papel das capacidades organizacionais. Tese (Doutorado em Administração) - Universidade de São Paulo, São Paulo, 2011.

BOTERF, G.. De la compétence: Essai sur un attracteur étrange, 1994. In: FLEURY, M. T. L.; FLEURY, A.. Construindo o conceito de competência. Revista de Administração Contemporânea, v.5, p.183-196, 2001

BRASIL. Decreto n.5707 de 23 fevereiro de 2006. Institui a Política e as Diretrizes para o Desenvolvimento de Pessoal da administração pública federal direta, autárquica e fundacional, e regulamenta dispositivos da Lei n.8112 de 11 de dezembro de 1990. Brasília: DOU, 2006.

BRASIL. Lei n.11091 de 12 de janeiro de 2005. Plano de Carreira dos Cargos Técnico Administrativos em Educação (e suas alterações). Brasília: DOU, 2005.
BRASIL. Lei n.8112 de 11 de dezembro de 1990. Dispõe sobre o regime jurídico dos servidores públicos civis da União, das autarquias e das fundações públicas federais. Brasília: DOU, 1990.

COSTA, L. V.; DUTRA, J.. Avaliação da carreira no mundo contemporâneo: proposta de um modelo de três dimensões. Revista de Carreiras e Pessoas, v.1, n.1, 2011.

DUTRA, J. S.. Competências: conceitos e instrumentos para a gestão de pessoas na empresa moderna. São Paulo: Atlas, 2004.

DUTRA, J. S.. Gestão por competências. São Paulo: Gente, 2001.

DUTRA, J. S.; FISCHER, A. L.; RUAS, R. D. L.; NAKATA, L. E.. Absorção do Conceito de Competência em Gestão de Pessoas: A Percepção dos Profissionais e as Orientações Adotadas pelas Empresas. Rio de Janeiro: ANPAD, 2006.

FERNANDES, B.. Gestão Estratégica de Pessoas: com foco em competências. Rio de Janeiro: Elsevier, 2013.

FISCHER, A.. Um resgate conceitual e histórico dos modelos de gestão de pessoas. In: FLEURY, M. T. L.. As pessoas na organização. São Paulo: Gente, 2002. p.11-34.

FLEURY, M. T. L.; FLEURY, A.. Construindo o conceito de competência. Revista de Administração Contemporânea, v.5, p.183-196, 2001.

FORTIS, M. F. A.. Orçamento orientado a resultados instrumento de fortalecimento democrático na América 
Latina?. Revista do Serviço Público, v.60, n.2, p.125-140, 2009.

GODOY, A. S.. Pesquisa Qualitativa: tipos fundamentais. Revista de Administração de Empresas, São Paulo, v.35, p.20-29, 1995.

HALL, D.. Career Development Comes of Age. Training \& Development Journal, v.40, n.11, p.16-18, 1986.

LEVY, B.. How technology changes demands for human skills. OECD Education Working Paper, Paris, v.45, p.1-18, 2010.

LIMA, I. V.. O sistema de remuneração dos servidores técnico-administrativos das IFES sob a lente da gestão de pessoas por competências. Gestão Pública: a visão dos Técnicos Administrativos em Educação das Universidades Públicas e Institutos Federais, v.3, p.67-79, 2016.

MCCLELLAND, D. C.. Testing for competence rather than intelligence. American Psychologist, Washington, n.28, p.14, 1973.

MCDONALD, P.; BROWN, K.; BRADLEY, L.. Have traditional career paths given way to protean ones? Evidence from senior managers in the Australian public sector School of Management. Faculty of Business. Barisbane: Queensland University of Tecnology, 2004.

MOTTA, P. R. M.. O estado da arte da gestão pública. Revista de Administração de Empresas, v.53, n.1, p.82-90, 2013. DOI: https://doi.org/10.1590/S0034-75901983000100015

PAIVA, K. C. M.; MELO, M. C. O. L.. Competências, Gestão de Competências e Profissões: Perspectivas de Pesquisas.

Revista de Administração Contemporânea, v.12, n.2, p.339,
2008. DOI: http://doi.org/10.1590/S141565552008000200004

PERRENOUD, P.. Construir as competências desde a escola. Porto Alegre: Artes Médicas, 1999.

PIRES, A. K.. Gestão por competências em organizações de governo. Brasília: ENAP, 2005.

RIBEIRO, A. L. Gestão de pessoas. São Paulo: Saraiva, 2006.

RUAS, R. L.; FERNANDES, B. H. R.; FERRAN, J. E. M.; SILVA, F. M.. Gestão por competências: revisão de trabalhos acadêmicos no Brasil no período 2000 a 2008. In: ENCONTRO DA ASSOCIAÇÃO NACIONAL DE PÓSGRADUAÇÃO EM ADMINISTRAÇÃO, 34. Anais. Rio de Janeiro: ANPAD, 2010

SANTOS, A. P.. Conhecimentos, habilidades e atitudes: o conceito de competências no trabalho e seu uso no setor público. Revista do Serviço Público, v.62, n.4, p.369-386, 2011.

SCHWARTZAM, S.. A abertura política e a dignificação da função pública. Revista do Serviço Público, v.41, n.2, p.43$57,2017$.

SOUZA, R. L. S.. Gestão por competências no governo federal brasileiro: experiência recente e perspectivas. In: CONGRESO INTERNACIONAL DEL CLAD SOBRE LA REFORMA DEL ESTADO Y DE LA ADMINISTRACIÓN PÚBLICA, 9. Anais. Madrid: Centro Latinoamericano de Administración para el Desarrollo, 2004.

ZARIFIAN, P.. Objetivo competência: por uma nova lógica. São Paulo: Atlas, 2008.

A CBPC - Companhia Brasileira de Produção Científica (CNPJ: 11.221.422/0001-03) detém os direitos materiais desta publicação. Os direitos referem-se à publicação do trabalho em qualquer parte do mundo, incluindo os direitos às renovações, expansões e disseminações da contribuição, bem como outros direitos subsidiários. Todos os trabalhos publicados eletronicamente poderão posteriormente ser publicados em coletâneas impressas sob coordenação da Sustenere Publishing, da Companhia Brasileira de Produção Científica e seus parceiros autorizados. Os (as) autores (as) preservam os direitos autorais, mas não têm permissão para a publicação da contribuição em outro meio, impresso ou digital, em português ou em tradução. 